\title{
Pathophysiology of changes in absolute lung volumes
}

\author{
E. Bancalari*, J. Clausen**
}

\begin{abstract}
Pathophysiology of changes in absolute lung volumes. E. Bancalari, J. Clausen. OERS Journals Ltd 1998.

ABSTRACT: Changes in absolute lung volumes are common in lung disease and result in significant impacts on gas exchange, respiratory muscle function, the sensation of dyspnoea, and limitations to maximal exercise. Though our knowledge regarding the magnitude and determinants of changes in lung volumes in health and disease has increased in the past 20 years, a number of important questions remain unanswered. Consideration of the limitations of specific methods for measuring lung volumes is essential when analysing published studies regarding absolute lung volumes in infants, children and adults. Though functional residual capacity is most commonly measured in children and adults with the subject awake and at rest, increasingly attention is being directed to making these measurements under clinically more relevant conditions (e.g. during exercise, sleep, anesthesia, or mechanical ventilation). The relationships between dynamic changes in functional residual capacity, flow limitation during tidal breaths, sensation of dyspnoea and exercise limitation are important to understand, and are the focus of current and future research. Improved understanding of these relationships may lead to improvements in therapy of patients with acute and chronic lung disease and are likely to be particularly important for evaluating the efficacy of and optimal patient selection for new modes of therapy, such as lung volume reduction surgery.
\end{abstract}

Eur Respir J 1998; 12: 248-258.

Changes in absolute lung volumes are an important outcome of many different types of lung disease and dysfunction. Changes in lung volumes are related to lung dysfunction and disease impact on lung mechanics, gas exchange, respiratory muscle function, the sensation of dyspnoea, and tolerance to maximal exercise.

An understanding of the physiological determinants of absolute lung volumes is helpful for optimizing the accuracy of these measurements, as lung volume measurements can be affected by test conditions (e.g. posture of the subject, volume history prior to the measurements). The physiological basis for changes in lung volumes in patients with lung disease is also important for understanding the clinical usefulness of these measurements and their role in evaluating new modes of therapy (e.g. lung volume reduction surgery) [1].

Though our understanding has improved in the past two decades, the determinants of pathophysiological changes in lung volumes remain incompletely defined [2-4]. Alterations in surface tension may have more impact on lung recoil $[5,6]$ in patients with a variety of diseases than previously recognized. Reflexes [7-12] which modify the net inspiratory and expiratory muscle force are additional but poorly understood possible determinants of changes in lung volumes which occur with disease.

As is the case with many aspects of physiology, consideration of the limitations of the methods for measuring absolute lung volumes is important when reviewing the literature on changes in lung volumes in disease. Lung volumes generally do not differ much in healthy adults whether measured by gas dilution, gas washout, body plethysmography, or radiographic techniques, even though the volumes measured are fundamentally different (communicating gas volumes, compressive gas volumes, and volumes within the boundaries of the thoracic cage, respectively). In infants or in adults with lung disease, however, these measurements may differ substantially and these differences must be considered when reviewing the pathophysiology of lung volume changes. Gas dilution or washout techniques may underestimate absolute lung volumes in infants $[13,14]$ and patients with bullous or obstructive airway disease $[15,16]$; body plethysmography may overestimate lung volumes if panting is done at inappropriately high frequencies [17].

\section{Physiological determinants of absolute lung volumes} in normal infants, children and adults

\section{Functional residual capacity}

"Static" or "relaxed" functional residual capacity (Vr) refers to an equilibration volume measured at times of no flow when chest wall muscles are relaxed and the elastic recoils of the chest wall and lung are equal and opposite in sign functional residual capacity (FRC) is most commonly measured at end-expiration during tidal breathing. When FRC is measured under more dynamic conditions as during mechanical ventilation, exercise, or other times when 
respiratory rates are increased, the volumes are frequently called dynamic FRC or end-expiratory lung volume (EELV). In normal adults at rest, EELV during tidal breathing usually equals $\mathrm{Vr}$.

Though the highly compliant thoracic cage of newborn infants facilitates the birth process, it provides an unstable structure for maintenance of lung volumes. In contrast to adults (where FRC usually equals $\mathrm{Vr}$ ), the FRC during normal tidal breathing in infants is considerably above Vr.

Measurements of $\mathrm{Vr}$ in infants are commonly as low as $10-15 \%$ of total lung capacity (TLC) in contrast with values of $\mathrm{Vr}$ of $30-35 \%$ of TLC in adults $[18,19]$. The chest walls of human infants stiffen within days of birth [20].

At the low volumes of $\mathrm{Vr}$ in normal infants, peripheral airway resistance is relatively high, the time constants for lung emptying are lengthened, and gas exchange may easily be impaired. EELVs are maintained above $\mathrm{Vr}$ in infants by the combination of reduced expiratory flows from increased laryngeal resistance $[21,22]$, maintenance of some diaphragmatic inspiratory muscle tone during expiration [8] and rapid respiratory rates with initiation of inspiration well before expiration reaches $\operatorname{Vr}[19,23]$. This elevation of EELV has the advantages of reduced airway resistance, less likelihood of airway collapse and atelectasis, and increased $\mathrm{O}_{2}$ stores.

During the growth of infants, the diameters of distal airways increase and elasticity of the chest wall decreases resulting in expiration becoming more passive between the ages of 6-12 months [23]. In normal adults at rest, changes in laryngeal resistance during tidal breathing may affect expiratory flows but are generally not considered to alter FRC. There is, however, evidence that upper airways may indeed play a role in defining FRC in normal adults at rest. Residual volume (RV), FRC, and TLC have been reported to increase after 6-8 weeks of intradental wiring (an intervention which forces airflow through the higher resistance in the nares) [24]. Conversely, FRC was observed to decrease after airflow was forced through the lower resistance oral passage following packing of the nasal passages to control haemorrhage. FRC was also noted to decrease following a decrease in nasal resistance resulting from surgery to relieve partial nasal obstruction [24].

In the first few minutes to hours after birth, the disappearance of foetal lung fluid is an important determinant of lung volumes [19]. It is likely that this shift in fluid contributes to the differences in lung volumes measured by different techniques during this period. Immediately after birth, in addition to increasing the EELV, glottal braking during expiration provides the additional advantage of promoting reabsorption of lung fluid during the first few minutes of life [25]. In children, FRC increases commensurate with increases in height; in adults, FRC changes minimally with ageing [26].

\section{Residual volume}

$\mathrm{RV}$ is defined as the absolute lung volume achieved after as much gas has been exhaled as is possible. Measurements of RV (or TLC) in infants are not possible because of the difficulties of reliably achieving maximal inspiratory and expiratory efforts. Absolute volume measure- ments in infants therefore are usually limited to the $\mathrm{Vr}$ or the FRC during tidal breathing.

In young healthy adults, RV is determined by the balance between expiratory muscle force (plus a small contribution from lung recoil) and the outward elastic recoil of the chest wall; if expiratory force is augmented by additional compressive pressure applied on the chest wall, the RV decreases [27]. Contractions of the diaphragms that have been observed to occur near the end of expiratory manoeuvres to RV may also limit the net expiratory force at RV [11].

In older normal adults, airway closure and flow limitation associated with decreases in elastic recoil with ageing contribute to the increase in RV noted with ageing [3]. In contrast with younger adults, when external compressive force is applied to the thoracic cage of older adults, RV decreases less or not at all [27].

\section{Total lung capacity}

TLC is determined by the balance of inward elastic forces of the chest wall and lung parenchyma and the outward forces generated by inspiratory muscles during a maximal inspiratory effort. Glottic closure or contraction of the antagonistic abdominal muscles may occur as TLC is approached and contributes to limitations in TLC in some subjects. These reactions can be overcome with training and may reflect unconscious aberrant responses to "unnatural" respiratory manoeuvres, rather than true determinants of TLC [7].

Increases in TLC in children relate to the increase in height [26] and concomitant increase in thoracic cage volumes during growth; in healthy adults, TLC does not change with ageing [26].

\section{Lung volume changes during exercise}

In normal adults, EELV during exercise differs from FRC at rest. During exercise, in younger adults without obstructive airway disease, increased activity of expiratory muscles [28] drives the EELV below FRC at rest [29]. This change shifts diaphragm function to a more optimal portion of the length-tension curve. It also has the advantage of increasing the outward recoil of the compressed thoracic cage at end-expiration which assists the inspiratory muscles during the subsequent inspiration, thereby shifting some of the work of breathing during exercise from inspiratory to expiratory muscles. In older normal adults, the changes in EELV are more variable and are related to limitations in maximal expiratory flows [30]. Elderly subjects with a progressive decrease in EELV with exercise have significantly higher maximal midflows than elderly subjects with progressive increases in EELV [30]. There is a paucity of studies on EELVs during exercise in children.

In healthy adults, TLC does not change with exercise $[29,31]$. The elevations of RV that have been observed in some [31] but not all [30] studies largely reflect limitations in time available for prolonged expiration during the tachypnea that accompanies exercise. 


\section{Lung volume changes during sleep}

Observations regarding changes in FRC in infants during sleep have been inconsistent. Some studies show decreases in FRC up to $30 \%[18,32]$, some only observed decreases when the rib cage and abdominal motion were out of phase [33], and others saw no changes [34].

In preterm infants, decreases in FRC during sleep seem to be secondary to decreases in inspiratory muscle tone during sleep [8] and decreases in lung volume after apnoeas, changes which are reversed by sighs that frequently follow apnoeas [33]. A decrease in laryngeal braking during expiration may also play a role. In adults, mean decreases in FRC of $10-17 \%$ have been reported during sleep [35, 36].

\section{Postural effects on lung volumes}

In normal adults, posture can affect absolute lung volumes. The magnitude of changes observed in different postures, however, differs considerably between different studies, probably reflecting differences in the pressure and volume history prior to measurements and the time course of measurements. FRC is the most affected volume; FRC is approximately $15 \%$ higher standing than sitting and 20 $25 \%$ lower when measured in the supine position as compared with sitting [37]. TLCs are approximately 5\% higher standing than sitting and $2-7 \%$ lower than sitting in the supine position [37, 38]. Changes in RV are problematic; $\mathrm{RV}$ increases of $\sim 25 \%$ have been observed when posture changes from sitting to standing [37]; most, but not all, studies show a decrease (e.g. 0-20\%) when posture is changed from sitting to supine $[37,38]$. The net impact on vital capacity (VC) in most studies is a decrease in VC when posture is changed from sitting to supine. In normal adults (aged 21-69 yrs), FVC decreased by an average of $7.5 \%$ when posture was changed from sitting to supine; $95 \%$ of the subjects had decreases of $<20 \%$ [39], changes primarily attributed to shifts in blood from the legs to the thorax [40].

\section{Changes in lung volumes in lung disease}

There are two general patterns of lung volume changes in disease: restriction and hyperinflation. These terms are widely used because they facilitate the recognition of characteristic patterns of lung disease.

\section{Restriction}

Restriction is a condition in which TLC is reduced, either as compared with predicted normal values or a patient's own baseline value of TLC when dysfunction was not present. VC is also usually reduced. Although these reductions of TLC and VC are most commonly accompanied by decreases in FRC and RV, decreases in FRC and/ or $\mathrm{RV}$ are not required to meet the definition of restrictive disease, as FRC or RV may be normal or even elevated in some patients with diseases otherwise categorized as restrictive.
Though frequently interrelated, causes of restriction can be attributed to six basic categories: lung growth, gas volume displacement, lung elastic recoil, pleural, neuromuscular, and thoracic cage abnormalities.

\section{Alterations in lung growth}

In infants and children, the main determinant of lung volume is the state of lung growth [20, 41-44]. In utero, any of the components of the respiratory system may be affected by deviations from the normal process of foetal maturation. The timing of deviations from this normal process will define the resultant changes in lung structure and function. The lung appears in the fourth week of gestation as a diverticulum of the foregut and airway branching is finished by the sixteenth week of gestation; early foetal abnormalities will impact on airway growth [20]. The alveoli first appear at 29 weeks of gestation; the number of alveoli increases later in gestation and continues to increase during early infancy [45].

A number of pathological processes can interfere with normal lung growth during intrauterine development or after birth. During fetal development, space occupying abnormalities in the chest can interfere with lung growth and reduce lung volume. Examples include congenital diaphragmatic hernias, accumulation of pleural fluid, and large tumours, or less commonly in malformations of the chest wall such as thoracic dystrophy and in neuromuscular diseases that interfere with chest wall development [46-48]. Intrauterine lung growth is also dependent on a normal production and volume of amniotic fluid. Hence, oligohydramnios associated with renal anomalies or amniotic fluid loss due to a premature rupture of the foetal membranes is frequently associated with varying degrees of pulmonary hypoplasia $[49,50]$. The severity of the lung hypoplasia depends on the time in gestation, the severity and the duration of the decrease in amniotic fluid volume. Amniocentesis [51] and administration of corticosteroids [52] are other factors that can affect infant lung volumes.

Although premature delivery will not adversely impact on the multiplication of alveoli, if mechanical ventilation is required, growth of the number of alveoli is slower than normal and there is an increase in collagen and elastin in the lung [53], with the result that the alveolar surface area is below normal and lower than expected for a given lung volume.

\section{Gas volume displacement}

Reductions in the volumes of airspaces (alveoli and alveolar ducts) occur as a result of compression or displacement of airspaces by fluids or abnormal tissue. At birth, the lung is filled with fluid that is, in normal circumstances, reabsorbed into the pulmonary circulation and lymphatics within a few hours, changes which are facilitated by the squeezing of the chest wall during vaginal delivery and positive airway pressures resultant from laryngeal braking during tidal breathing [25]. Under certain conditions, including birth by Caesarean section, pulmonary artery hypertension and heart failure, this reabsorption is delayed, interfering with the normal expansion of lung volumes [54-56]. The same can occur when pulmonary blood volume is increased due to obstruction of the 
pulmonary venous return, increased pulmonary blood flow due to left to right cardiac shunting or when hypervolemia occurs due to late clamping of the umbilical cord [57].

Additional specific causes of gas volume displacement include: 1) pulmonary oedema [58]; 2) inflammatory fluids and tissue in the alveoli or interstitium, as occurs in pneumonia [58] or an inflammatory interstitial process; 3 ) interstitial fibrosis; 4) engorgement of the pulmonary vascular bed and cardiomegaly as seen in congestive heart failure (CHF); 5) hypertrophy, hyperplasia, and fibrosis of the pulmonary vascular bed as has been reported in chronic pulmonary hypertension [59]; 6) tumours either within the lungs or impinging on the lungs from the pleura or mediastinum; 7) large pleural fluid accumulation; and 8) pneumothorax.

\section{Decreases in lung compliance, increases in lung recoil}

Reductions in the distensibility of the lungs and increases in elastic recoil can result in substantial decreases in TLC and lesser decreases in FRC and RV. The specific determinants include both tissue elasticity and surface tension. Data from a variety of mammals [5] indicate that surface forces are the major determinants of variations in lung distensibility in air-filled alveoli, although alveolar micromechanics studies indicate that the surface tension is more important at lower than higher lung volumes [60]. The exact role of surface tension in changes of lung volumes, and the relationship between decreases in alveolar size and surface tension in parenchymal lung disease remains controversial.

Leakage of plasma proteins into the alveolar space or the presence of substances associated with inflammation or lung injury may alter the surface tension of the alveoli with resultant additional impact on the distensibility of the lung [61-63]. Increased surface tension as a contributing cause of increased elastic recoil of the lung has been observed in rats with bleomycin-induced pulmonary fibrosis [64]. Accumulation of fluid can also affect lung distensibility by the complex effects of deformations of parenchymal boundaries [65].

In the newborn, the most common cause of respiratory failure is respiratory distress syndrome (RDS) that is characterized by diffuse alveolar collapse and decreased FRC [66-72]. The main underlying mechanism for the alveolar collapse is a decreased production and inactivation of surfactant in the alveolar surface. The collapsing tendency of the alveoli is coupled with an increased chest wall compliance due to prematurity, leading to a marked and progressive reduction in lung volume [73]. Administration of exogenous surfactant to infants with RDS results in a rapid increase in lung volume [74].

Interstitial or alveolar accumulation of fluid or fibrous tissue such as observed in infants with pneumonia, pulmonary oedema or bronchopulmonary dysplasia (BPD) also can result in a marked reduction in lung compliance and FRC $[58,75]$.

Although decreases in lung compliance clearly are an important cause of reductions in lung volumes, review of pulmonary volume (PV) curves from some patients with interstitial disease and reduced TLCs attributed to reductions in lung compliance shows, that the pleural pressures at maximal inspiration are not as negative as one would expect [76-79]. BRADVIK et al. [79] speculated that inflammatory activity at the site of mechanical receptors may be responsible for these lower-than-expected maximal transpulmonary pressures; the observations also give support to the hypotheses offered by MEAD et al. [7] on the role for reflex inhibition of inspiration through activation of expiratory muscles.

Specific causes of reduced parenchymal compliance also include any process which results in abnormal accumulations of tumour cells within the lung interstitium or visceral pleura, intra-alveolar and interstitial fluid as occurs with $\mathrm{CHF}$, and inflammation and fibrosis in the interstitium. In addition, reductions in lung volumes have been attributed to reduced distensibility of the pulmonary vascular bed in patients with chronic pulmonary hypertension and resultant reduction in lung distensibility [59]. Finally, neuromuscular disease can be associated with reductions in lung distensibility [80]; the specific mechanisms may include microatelectasis or the effects of reduced alveolar size on surface tension [5].

\section{Abnormalities of the pleura}

Decreases in lung volume can be caused by reductions in lung compliance from fibrosis, tumour, or inflammation involving either the parietal or visceral pleura. Many pleural processes may also cause compression or limitation of airspace expansion in the lungs, resulting in reductions in TLC (reductions which may be magnified in the presence of inspiratory muscle weakness). Examples include reversible diaphragmatic paresis associated with inflammation adjacent to the diaphragm, or phrenic nerve dysfunction secondary to invasion from carcinoma.

\section{Neuromuscular disease}

Any disease or injury which causes a decrease in inspiratory muscle strength can result in decreases in TLC. In addition, the resultant chronic reductions in alveolar size can result in further reductions in lung volumes from the effects of microatelectasis and alterations in surface tension forces of the alveoli and airways [80-82].

Diaphragmatic paralysis due to birth or surgical trauma to the phrenic nerve is seen in neonates and infants and can result in greater than expected decreases in FRC because of the elevation of the weakened diaphragm and a highly compliant chest wall. In addition to generalized neuromuscular diseases (e.g. myasthenia gravis), more localized processes such as spinal cord tumours or peripheral nerve injuries can result in selective impairment of function in either inspiratory or expiratory muscles. Diseases or trauma which affect expiratory muscles can result in increases in RV [80, 82], changes which are often accentuated in the supine position.

\section{Thoracic cage abnormalities}

Alterations in the mechanical properties or in the configuration of the chest wall can have a marked influence on lung volume. The increased compliance of the chest wall in small preterm infants is an important factor that favours excessive lung emptying during expiration and is 
partly responsible for the reduced FRC in these infants. With increasing age and maturity, the rigidity of the chest wall increases, providing more stability to the respiratory system [73]. Severe congenital chest wall deformities can result in reduced FRC.

Reductions of FRC or TLC can occur from any process which limits expansion of the thoracic cage, including processes which limit the caudal movements of the diaphragms. A number of intra-abdominal processes can push the diaphragm up or limit its movement down including ascites, pregnancy, intra-abdominal tumours, severe obesity, and even normal gastric filling from eating [83]. These reductions will be even more pronounced when the patient is in the supine or prone positions due to increased cephalic pressure on the diaphragms. The impact of abdominal processes may also be accentuated during sleep when the contributions of accessory muscles in maintaining FRC are reduced.

In obesity, the observations of RAY et al. [84] indicate that TLC is reduced only when obesity is very severe (e.g. when weight in $\mathrm{kg}$ exceeds height in $\mathrm{cm}$ ), though spirometric data from population studies show modest reductions in VC (and presumably in TLC) associated with lesser degrees of obesity [85]. The observed increases in TLC (e.g. 4-20\%) that have been reported in obese adults who have undergone varying degrees of weight reduction suggest that excessive weight may decrease TLC, even if obesity is not severe. However, the interpretation of these data is complicated by the failure of most studies to monitor for improvements in sleep-related disturbances in respiration which frequently accompany weight loss and which could also improve lung volumes by reducing cor pulmonale. Reductions in TLC may occur with obesity of less severity in the elderly or in those with neuromuscular disease.

In the subgroup of patients with obesity hypoventilation, VC and TLC are often substantially less than is observed in weight-matched obese patients without the hypoxaemia and $\mathrm{CO}_{2}$ retention typical of the obesity-hypoventilation syndrome [86, 87]. Possible mechanisms for these reductions in lung volumes include: abnormal load compensation secondary to impaired respiratory neuromuscular coupling [86], both right and left-sided heart failure secondary to desaturation from obstructive or central apnoeas, hypopnoeas, or hypoventilation during sleep [87]; or fatty infiltration of the diaphragm [88]. This restriction is frequently improved substantially after effective treatment of sleep apnoea, or after weight loss of a magnitude which would not be expected to change lung volumes significantly but which is associated with significant improvements in ventilation during sleep.

Other causes of reduced TLCs classified under chest wall abnormalities include tumours or inflammatory masses of the chest wall and acquired malformations of the chest wall, such as ankylosing spondylitis or kyphoscoliosis.

Kyphoscoliosis can result in profound reductions in TLC and VC, although the RV is often close to normal. These changes are attributable to respiratory muscle dysfunction, as well as the deformities in the thoracic cage [89]. Lung compliance is reduced similar to the pattern resultant from chest wall strapping of normal subjects [90]. Reports of substantial increases in lung volumes and maximal inspiratory pressures, and improvements in gas exchange following nocturnal assisted ventilation [91] suggest that factors other than muscle weakness and atelectasis (e.g. respiratory muscle fatigue or alterations of surface tension from increases in alveolar size) may contribute to the profound reductions in lung volumes and resultant respiratory failure so typical of the late stages of this disease.

Although pectus excavatum can be associated with decreases in $\mathrm{VC}$ and elevations of RV, in the absence of coexisting lung disease, TLC is usually normal [92]. The limitation of rib cage mobility is associated with increased abdominal pressures during inspiration, but this would seem to be independent of the symptoms of dyspnoea which these patients sometimes have [93].

\section{Hyperinflation}

As is the case with restriction, there is no universally agreed definition of hyperinflation. In general, the term refers to elevations of absolute lung volumes (RV, FRC and TLC). Some use the term to refer only to elevations of $\mathrm{RV}$ or the RV/TLC ratio, others refer to increases in FRC, while others reserve hyperinflation to describe conditions where there are elevations of TLC. In this review, we will refer to the specific lung volume when using the term "hyperinflation".

Hyperinflation of TLC. General causes include obstructive lung diseases and diseases which cause the loss of elastic recoil of the lung. Obstructive lung diseases which are commonly associated with elevations of TLC include asthma, chronic bronchitis, emphysema and bronchiolitis. Elevated lung volumes associated with bronchiolitis in infants can persist for more than a year after the acute episode [94]. The physiological and clinical consequences of hyperinflation were well reviewed recently by GIBSON [95].

In infants during the first days of life, measurements of lung volumes have shown larger values for EELV by plethysmography than by gas dilution techniques, suggesting the presence of gas trapping due to small airway closure [96]. It is possible that at least some of these differences in volumes are due to technical limitations of body plethysmography performed on small infants [9798]. Pathological conditions in infancy characterized by hyperinflation include meconium aspiration syndrome [99], bronchopulmonary dysplasia [100] and bronchiolitis or asthma.

Though the development of clinically significant emphysema in children with alpha-1-antitrypsin deficiency (AAD) is generally considered to be uncommon, an increased prevalence of hyperinflation of FRC was reported in 28 children with AAD (median age 5.7 yrs, range 2-16 yrs) [101]. Partial support for these observations include the observation of elevated FRCs (mean $=133 \%$ of predicted) observed in 22 AAD children (mean age 15.1 yrs) despite mean values of forced expiratory volume in one second (FEV1) and mid-expiratory flow (FEF25-75\%) of 99 and $95 \%$, respectively [102]. The absence of pulmonary function tests (PFTs) in control children, the difficulties in predicting PFTs in children, and the current lack of follow-up during adulthood in these studies limits conclusions, but does indicate a need for improved studies of hyperinflation in young patients with AAD in the future. 
In adults, although the loss of elastic recoil as occurs in emphysema or bullous disease is usually also associated with evidence of airway obstruction, there are some patients who have evidence of bullous disease or reduced recoil from emphysema without clinically recognizable reductions in maximal expiratory flows [103]. Similarly, patients have been reported to have significant elevations of RV without abnormalities of FEV1, presentations that were attributed to early emphysema [104, 105]. In asthma, "isolated" elevations of RV may also occur in the absence of recognizable decrements in maximal flow rates [106].

Measurements of absolute lung volumes by gas dilution or washout techniques may be lower than the same measurements by plethysmography or radiographic techniques even when plethysmography is done using techniques to avoid artifactual elevations. The reported underestimates of absolute lung volumes by gas dilution or washout techniques and overestimates of lung volumes attributed to excessively high panting frequencies during plethysmography have reduced the confidence we can place in many previous observations regarding hyperinflation in the literature [95].

The pathophysiology of hyperinflation of TLC remains incompletely understood [2-4, 95, 107]. In ex vivo studies of lungs from patients with mild emphysema, reductions in elastic recoil and elevations of TLC have been observed in the absence of functionally significant obstruction of small airways [108]. Studies of patients with more severe emphysema showed highly significant correlations between the magnitude of hyperinflation of TLC and the severity of emphysema defined pathologically [109].

The traditional explanation of elevations of TLC in obstructive airway disease include reductions in elastic recoil of the lung from emphysema. Reversible decreases in elastic recoil in asthmatics have been described, but the validity of these observations is controversial [110], as previously described shifts of the PV curves to the left may have been secondary to plethysmographic overestimates of lung volumes. Nevertheless, substantial acute reductions in TLC following therapy of acute exacerbations of asthma have been documented by gas dilution and qualitative assessments of chest radiographs [111]. Smaller acute decreases in TLC following therapy for asthma have also been confirmed by radiographic planimetric measurements [112]. Possible mechanisms include changes in alveolar size $[113,114]$ and secondary effects on pulmonary elasticity attributable to alterations in surface tension forces $[5,6,115]$. Other possibilities include alterations in reflex limitations on inspiratory muscle force [7].

It is likely that the largest acute changes in TLC secondary to exacerbations or treatment of asthma will occur in infants and children because of their increased chest wall compliance, but literature documenting this is sparse. However, it has been observed that in adult asthmatics who had the onset of asthma before the age of $8 \mathrm{yrs}$, TLCs were elevated in comparison with the normal TLCs of otherwise matched adult asthmatics who had the onset of asthma after the age of 18 yrs [114]. In early adolescents, Merkus et al. [116] observed an initial larger TLCs than in age- and height-matched controls. They also reported less growth in TLC $\cdot \mathrm{yr}^{-1}$ during adolescence in asthmatics than controls, but normal growth rates when corrected for the smaller stature were attributable to delayed pubertal development. They concluded that the increased TLCs in adolescents with childhood asthma were more consistent with greater alveolar growth during childhood, and delays in pubertal development, rather than loss of elastic recoil of the lung.

Hyperinflation of $F R C$. The high respiratory rate of small infants usually results in an increase in EELV volume above their Vr. This is even more striking in infants with airway obstruction who have a prolonged time constant of the lungs [117], as observed in some newborns with meconium aspiration syndrome [99], in infants with bronchopulmonary dysplasia [100, 118] and in infants with bronchiolitis or asthma. Emphysema and bullae associated with more severe cases of bronchopulmonary dysplasia [118] can reduce lung recoil, although airway obstruction also contributes to the elevation of EELV characteristically observed in these patients.

EELV is maintained above $\mathrm{Vr}$ by active closure of the upper airway during expiration (grunting) in infants with respiratory distress syndrome (RDS) [21, 22]. This closure allows maintenance of more normal lung volumes in the presence of surfactant deficiency and chest wall instability. This protective braking is, however, lost during endotracheal intubation and must be replaced with positive end-expiratory pressure to avoid a loss in lung volume. In adult asthmatics, reduction in glottal lumen after bronchial challenge has been noted; the observations suggested active expiratory glottic constriction, but decreased dilator activity could not be ruled out [119].

In adults as well as infants, a commonly recognized additional cause of hyperinflation of FRC is insufficient time for complete expiration to the "equilibrium" point before inspiration [117, 118, 120]. In some conditions where FRC is hyperinflated, "post-inspiratory" activity of the inspiratory muscles has been observed that causes retardation of expiration and resultant increases in endexpiratory lung volume $[8,121,122]$. During active sleep, some of these volume-preserving mechanisms may be lost and result in a decrease in lung volume and deterioration of gas exchange $[18,33]$.

The specific mechanisms responsible for triggering increases in inspiratory muscle activity, persistence of inspiratory muscle tone during expiration, and expiratory laryngeal braking, are not clear. Recent evidence has been presented that expiratory flow limitation during tidal breathing is a critical stimulus for increases in FRC, both during drug-induced bronchoconstriction [123] and during exercise [10]. Dynamic compression of the airways may also play an important role [124].

Causes of chronic elevations of FRC, as opposed to acute and reversible changes of FRC, may include hypertrophy and changes in length-tension relationships of inspiratory muscles $[3,125]$. It is not clear whether the inspiratory muscle activity during expiration found in acutely induced bronchoconstriction also persists in more prolonged or chronic states of hyperinflation.

Finally, chronic elevations of FRC can result in changes in the thoracic cage which persist even after the airway disease responsible for the hyperinflation is improved or resolved. Evidence for this includes persisting elevations in FRC in patients with cystic fibrosis after heart-lung transplant [126]. The observation that elevated FRCs returned to within normal limits in three patients with hyperinflation of FRC from causes other than cystic fibrosis 
[126] suggests that the development of hyperinflation during childhood may result in irreversible changes in chest wall volume that are not observed if the hyperinflation starts after childhood, although studies of greater numbers of patients are needed to confirm this conclusion. Additional support for this hypothesis comes from the observations that FRCs (and TLCs) were larger in asthmatics who had onset of asthma before the age of 8 yrs than in those with onset after $18 \mathrm{yrs}$ of age, despite equivalent degrees of airflow obstruction [114].

Hyperinflation of $R V$. In both elderly healthy adults and individuals with obstructive lung disease, early closure or compression of small airways during expiration is considered a key determinant of the frequently observed elevations of RV. Air trapping is important in some patients [127]. In addition, increases in inspiratory muscle tone at the end of expiration [11] may play a role.

\section{Lung volume changes during exercise}

In patients with chronic obstructive pulmonary disease (COPD), significant increases in EELV have been noted during exercise [95]. Patients with greater exertional dyspnoea had larger dynamic hyperinflation of FRC during exercise; the greater the dynamic hyperinflation, the less the patients were able to increase tidal volume $(V \mathrm{~T})$ during exercise [128].

Increases in EELV during exercise in COPD are generally attributed to insufficient time during expiration before the next inspiration. There may also be increases in inspiratory muscle drive secondary to perceptions of unpleasant respiratory stimuli associated with dynamic airway compression resulting from transpulmonary pressures which exceed the critical pressure at which airway compression occurs [129] and/or secondary to limitations in expiratory airflow [123].

Although dynamic hyperinflation of EELV during exercise in patients with COPD decreases airway resistance with resulting decreases in the work of breathing, it does so at the expense of working against higher lung and chest wall recoil, a worsened mechanical advantage of inspiratory muscles, and loss of the potential for sharing the respiratory workload with expiratory muscles. In patients with severe emphysema, reduction in hyperinflation of FRC during exercise is likely to be a key outcome of lung volume reduction surgery.

Changes in FRC during anaesthesia, mechanical ventilation and breathing $100 \%$ oxygen

In normal adults, FRC decreases during anaesthesia by 15-30\% whether or not accompanied by muscle relaxation $[130,131]$. The changes are partially but not completely reversed following repeated lung inflations [132]. Similar decreases have been noted in infants and children [133]. Comparable decreases in FRC have also been observed in unconscious patients who have sustained head injuries.

The mechanisms for the decreases in FRC with anaesthesia are controversial and not completely defined. The observed shifts in the lung PV curve to the right are similar to those observed after chest binding and may be sec- ondary to changes in lung surface forces associated with periods of low-volume breathing [6]. Decreases in inspiratory muscle tone, airway closure and subsequent atelectasis, cephalad movement of the diaphragm, and decreases in compliance of both the lung and chest wall have also been suggested as causes [130-132, 134]. The smaller changes in thoracic cage dimensions after anaesthesia, observed utilizing measures of thoracic dimensions [135] and computed tomography (CT) estimates of thoracic cage volume [136], suggest that increases in intrathoracic fluid may play a contributory or dominant role.

In contrast with patients of normal weight range, morbidly obese patients have been observed to have much larger decreases in FRC during anaesthesia (e.g. 50\% reductions in FRC). This can result in FRCs decreasing to levels below the patients' RV when awake. In obese patients it has been observed that lung volume increased during laparotomy (presumably from a decrease in intra-abdominal tension) and recurred again after closure of the laparotomy [137].

In patients on mechanical ventilation, it has been observed that expiratory muscles are activated when end-expiratory positive pressures exceed $10 \mathrm{cmH}_{2} \mathrm{O}$. This is a likely explanation for why muscle relaxants are useful in patients with respiratory failure treated with continuous positive airway pressure (CPAP), in whom expiratory muscle activation seems to limit the increases in lung volumes which would otherwise accompany CPAP [12].

In infants, breathing $100 \% \mathrm{O}_{2}$ has been shown to reduce lung volumes [138], although the effects on measurements of volumes by the nitrogen washout technique are not defined [139]. Breathing 100\% oxygen for $10 \mathrm{~min}$ at lung volumes below closing capacities has been shown to decrease RV by an average of $500 \mathrm{~mL}$ in normal adult subjects [140]. Volumes did not decrease if the subjects were breathing at volumes above closing capacities during $\mathrm{O}_{2}$ administration. These observations support the reports of decreases in FRC of, on average, 12\% after breathing high concentrations of $\mathrm{O}_{2}$ for 3-5 min [141], changes which are readily reversible and different from the more serious decreases in lung volumes after Š5 days of $100 \% \mathrm{O}_{2}$ breathing attributed to lung injury. The dependence of decreases in volumes on the relationship between closing capacity and EELV during $\mathrm{O}_{2}$ administration may explain why lung volumes do not decrease acutely in all patients after administration of $100 \% \mathrm{O}_{2}$.

\section{Changes in lung volumes during sleep in patients with respiratory disease}

Though there are many publications regarding the monitoring of oxyhaemoglobin desaturation during sleep in patients with a variety of respiratory diseases, there are relatively few which report on changes in FRC during sleep. In clinically stable patients with mild asthma, but histories of nocturnal worsening, BALLARD et al. [35] noted greater decreases in plethysmographically measured FRCs during sleep than in healthy controls ( 30 versus $17 \%$ ). In the asthmatics, the nocturnal decreases in airway conductance were greater than expected for the decrease in lung volumes observed. On awakening, the asthmatics rapidly increased their FRCs to levels higher than the mild hyperinflation of FRC they had prior to sleep. Chest strapping 
during the day to achieve decreases in FRC of the same magnitude observed during sleep led to sustained and substantial decreases in FEV1, changes similar to the drops in FEV1 noted in the same patients after arising from sleep. These decrements in FEV1 persisted even after the chests were unstrapped and the subjects took deep breaths over a 10-min period. The mechanisms for the observed decreases in FRC during sleep and why such decreases in volumes resulted in persisting decrements in maximal airflows in these asthmatics remains unclear. Given the frequency of nocturnal worsening in asthmatics, the impact of sleep on lung volumes and airway function remains an important area for future research.

Patients with dysfunction of inspiratory muscles, as can occur with neuromuscular disease or severe kyphoscoliosis, may have profound desaturation during sleep. Although there is a paucity of reported studies of lung volume changes during sleep in such patients, it is likely that decreased lung volumes during sleep are an important contributing factor in addition to the hypoventilation during sleep that has commonly been observed. The observation that awake daytime measurements of maximum inspiratory mouth pressure and lung volumes increase after nocturnal continuous positive airway pressure or ventilatory support in such patients indicates that worsening of inspiratory muscle function during sleep has effects on lung volumes which persist during the day and which can be reversed with nocturnal ventilation [91].

\section{References}

1. Russi E, Stammberger U, Weder W. Lung volume reduction surgery for emphysema. Eur Respir J 1997; 10: 208 218.

2. Demedts M. Mechanisms and consequences of hyperinflation. Eur Respir J 1990; 3: 617-618.

3. Macklem PT. Hyperinflation (editorial). Am Rev Respir Dis 1984; 129: 1-2.

4. Brusasco V, Fitting JW. Lung hyperinflation in airway obstruction. Eur Respir J 1996; 9: 2440.

5. Haber PS, Colebatch HJ, Ng CK, Greaves LA. Alveolar size as a determinant of pulmonary distensibility in mammalian lungs. J Appl Physiol 1983; 54: 837-845.

6. Young SL, Tierney DF, Clements JA. Mechanism of compliance change in excised rat lungs at low transpulmonary pressure. J Appl Physiol 1970; 29: 780-785.

7. Mead J, Milic-Emili J, Turner JM. Factors limiting depth of a maximal inspiration in healthy subjects. J Appl Physiol 1963; 18: 295-296.

8. Lopes J, Muller NL, Bryan MH, Bryan AC. Importance of inspiratory muscle tone in maintenance of FRC in the newborn. J Appl Physiol 1981; 51: 830-834.

9. Kosch PC, Davenport PW, Wozniak JA, Stark AR. Reflex control of inspiratory duration in newborn infants. $J$ Appl Physiol 1986; 60: 2007-2014.

10. Pellegrino R, Brusasco V, Rodarte JR, Babb TG. Expiratory flow limitation and regulation of end-expiratory lung volume during exercise. J Appl Physiol 1993; 74: 25522558.

11. Agostoni E, Torri G. Diaphragm contraction as a limiting factor to maximum expiration. J Appl Physiol 1962; 17: 427-428.

12. Chandra A, Coggeshall JW, Ravenscraft SA, Marini JJ. Hyperpnea limits the volume recruited by positive end- expiratory pressure. Am J Respir Crit Care Med 1994; 150: 911-917.

13. Gappa M, Fletcher ME, Dezateux CA, Stocks J. Comparison of nitrogen washout and plethysmographic measurements of lung volume in healthy infants. Am Rev Respir Dis 1993; 148: 1496-1501.

14. American Thoracic Society/European Respiratory Society. Respiratory mechanics in infants; physiologic evaluation in health and disease. Am Rev Respir Dis 1993; 147: 474-496.

15. Tierney DF, Nadel JA. Concurrent measurements of functional residual capacity by three methods. J Appl Physiol 1962; 17: 871-873.

16. Bedell GN, Marshall R, DuBois AB, Comroe JH Jr. Plethysmographic determination of gas trapped in the lungs. J Clin Invest 1956; 35: 664-670.

17. Rodenstein DO, Stanescu DC, Francis C. Demonstration of failure of body plethysmography in airway obstruction. J Appl Physiol 1982; 52: 949-954.

18. Stark AR, Cohlan BA, Waggener TB, Frantz ID, Kosch PC. Regulation of end-expiratory lung volume during sleep in premature infants. J Lab Physiol 1987; 62: 11171123.

19. Polgar G, Weng TR. The functional development of the respiratory system from the period of gestation to adulthood. Am Rev Respir Dis 1979; 120: 625-695.

20. Hislop A, Haworth SG. Airway size and structure in the normal fetal and infant lung and the effect of premature delivery and artificial ventilation. Am Rev Respir Dis 1989; 140: 1717-1726.

21. Lindroth M, Johnson BD, Ahlstrom H, Svenningsen NW. Pulmonary mechanics in early infancy. Subclinical grunting in low-birth-weight infants. Pediatr Res 1981; 15: 979984.

22. Harrison VC, Heese HV, Klein M. The significance of grunting in hyaline membrane disease. Pediatrics 1968; 41: 549-559.

23. Taussig LM, Helms PJ. Basic physiology. In: Stocks J, Sly PD, Tepper RS, Morgan WJ, eds. Infant Respiratory Function Testing. New York, Wiley-Liss, 1996; pp. 9-12.

24. Swift AC, Campbell IT, McKown TM. Oronasal obstruction, lung volumes, and arterial oxygenation. Lancet 1988; i: $73-75$.

25. Bryan AC, England SJ. Maintenance of an elevated FRC in the newborn. Am Rev Respir Dis 1984; 129: 209-210.

26. Stocks J, Quanjer PH. Reference values for residual volume, functional residual capacity and total lung capacity. Eur Respir J 1995; 8: 492-506.

27. Leith DE, Mead J. Mechanisms determining residual volume of the lungs in normal subjects. J Lab Physiol 1967; 23: 221-227.

28. Campbell EJM. An electromyographic study of the role of abdominal muscles in breathing. J Physiol (Lond) 1952; 117: 222-233.

29. Babb TG, Rodarte JR. Lung volumes during low-intensity steady-state cycling. J Lab Physiol 1991; 70: 934937.

30. Johnson BD, Reddan WG, Pegelow DF, Seow KC, Dempsey JA. Flow limitation and regulation of functional residual capacity during exercise in a physically active aging population. Am Rev Respir Dis 1991; 143: 960967.

31. Stubbing DG, Pengelly LD, Morse JLC, Jones NL. Pulmonary mechanics during exercise in subjects with chronic airflow obstruction. J Appl Physiol 1980; 49: 511-515.

32. Poets CF, Rau GA, Neuber K, Gappa M, Seidenberg J. Determinants of lung volume in spontaneously breathing 
preterm infants. Am J Respir Crit Care Med 1997; 155: 649-653.

33. Henderson-Smart DJ, Read DJC. Reduced lung volume during behavioral active sleep in the newborn. $J$ Appl Physiol 1979; 46: 1081-1085.

34. Beardsmore CS, MacFadyen UM, Moosavi SS, Wimpress SP, Thompson J, Simpson H. Measurement of lung volumes during active and quiet sleep in infants. Pediatr Pulmonol 1989; 7: 71-77.

35. Ballard RD, Irvin CG, Martin RJ, Pak J, Pandey R, White DP. Influence of sleep on lung volume in asthmatic patients and normal subjects. J Lab Physiol 1990; 68: 20342041.

36. Hudgel DW, Devadatta P. Decrease in functional residual capacity during sleep in normal humans. $J$ Lab Physiol 1984; 57: 1319-1322.

37. Briscoe WA. Lung volumes. In: Fenn WO, Rahn H, eds. Handbook of Physiology: Respiration, Section 3. Washington, DC, American Physiological Society, 1965; pp. 1363-1365.

38. Whitfield AGW, Waterhouse JAH, Arnott WM. The total long volume and its subdivisions. II. The effects of posture. Br J Social Med 1950; 4: 113-116.

39. Allen SM, Hunt B, Green M. Fall in vital capacity with posture. Br J Dis Chest 1985; 79: 267-271.

40. Estenne M, De Troyer A. Mechanism of the postural dependence of vital capacity in tetraplegic subjects. Am Rev Respir Dis 1987; 135: 367-371.

41. Taussig LM, Harris TR, Lebowitz MD. Lung function in infants and young children: functional residual capacity, tidal volume, and respiratory rats. Am Rev Respir Dis 1977; 116: 233-239.

42. Gerhardt T, Reifenberg L, Hehre D, Feller R, Bancalari E. Functional residual capacity in normal neonates and children up to 5 years of age determined by a N2 washout method. Pediatr Res 1986; 20: 668-671.

43. Tepper RS, Morgan WJ, Cota K, Wright AL, Taussig LM. Physiologic growth and development of the lung during the first year of life. Am Rev Respir Dis 1986; 134: 513-519.

44. Masters IB, Seidenberg J, Hudson IL, Phelan PD, Olinsky A. Longitudinal study of lung mechanics in normal infants. Pediatr Pulmonol 1987; 3: 3-7.

45. Hislop A, Wigglesworth JS, Desai R. Alveolar development in the human fetus and infant. Early Hum Dev 1986; 13: $1-11$.

46. Helms P, Stocks J. Lung function in infants with congenital pulmonary hypoplasia. J Pediatr 1982; 101: 918922.

47. Nakayama DK, Motoyama EK, Mutich RL, Koumbourlis AC. Pulmonary function in newborns after repair of congenital diaphragmatic hernia. Pediatr Pulmonol 1991; 11: 49-55.

48. Cunningham M, Stocks J. Werdnig-Hoffman disease: the effects of intrauterine onset on lung growth. Arch Dis Child 1978; 53: 921-925.

49. Hislop A, Hey E, Reid L. The lungs in congenital bilateral renal agenesis and dysplasia. Arch Dis Child 1979; 54: $32-38$.

50. Thibeault DW, Wong MM, Auld PA. Thoracic gas volume changes in premature infants. Pediatrics 1967; 40: 403-411.

51. Hislop A, Fairweather DV, Blackwell RJ, Howard S. The effect of amniocentesis and drainage of amniotic fluid on lung development in Macaca fascicularis. Br J Obstetr Gyn 1984; 91: 835-842.

52. Tschanz SA, Damke BM, Burri PH. Influence of postna- tally administered glucocorticoids on rat lung growth. Biol Neonate 1995; 68: 229-245.

53. Hislop A, Wigglesworth JS, Desai R, Aber V. The effects of preterm delivery and mechanical ventilation on human lung growth. Early Hum Dev 1987; 15: 147-164.

54. Klaus M, Tooley WH, Weaver KH, Clements JA. Lung volume in the newborn infant. Pediatrics 1962; 111-116.

55. Milner AD, Saunders R, Hopkin E. The effect of continuous positive airway pressure on lung mechanics and lung volume in the neonate. Biol Neonate 1976; 29: 178.

56. Boon AW, Milner AD, Hopkin E. Lung volumes and lung mechanics in babies born vaginally and by elective and emergency lower segmental cesarean section. J Pediatr 1981; 98: 812-815.

57. Oh W, Wallgren G, Hanson JS, Lind J. The effects of placental transfusion on respiratory mechanics of normal term newborn infants. Pediatrics 1967; 40: 6-12.

58. Sivan Y, Deakers TW, Newth CJ. Functional residual capacity in ventilated infants and children. Pediatr Res 1990; 28: 451-454.

59. Horn M, Ries AL, Neveu C, Moser K. Restrictive ventilatory pattern in precapillary pulmonary hypertension. Am Rev Respir Dis 1983; 128: 163-165.

60. Bachofen H, Schurch S, Urbinelli M, Weibel ER. Relations among alveolar surface tension, surface area, volume, and recoil pressure. J Appl Physiol 1987; 62: 1878-1887.

61. Balis JU, Shelley SA, McCue MJ, Rappaport ES. Mechanism of damage to the lung surfactant system: ultrastructure and quantitation of normal and in vitro inactivated lung surfactant. Exp Mol Pathol 1971; 14: 243-262.

62. Seeger W, Stohn G, Wolf HRD, Neuhof H. Alteration of surfactant function due to protein leakage: special interaction with fibrin monomer. $J$ Appl Physiol 1985; 58: 326-328.

63. Hallman M, Spragg R, Harrell JH, Moser KM, Gluck L. Evidence of lung surfactant abnormality in respiratory failure: study of bronchoalveolar lavage phospholipids, surface activity, phospholipase activity, and plasma myoinositol. J Clin Invest 1982; 70: 673-683.

64. Horiuchi T, Ikegami M, Cherniack RM, Mason RJ. Increased surface tension of the lung and surfactant in bleomycin-induced pulmonary fibrosis in rats. Am J Respir Crit Care Med 1997; 154: 1002-1005.

65. Smith JC, Mitzner W. Elastic characteristics of the lung perivascular interstitial space. J Appl Physiol 1983; 54: 1717-1725.

66. Thibeault DW, Beatty ECJ, Hall RT, Bowen SK, O'Neill DH. Neonatal pulmonary hypoplasia with premature rupture of fetal membranes and oligohydramnios. J Pediatr 1985; 107: 273-277.

67. Tori CA, Krauss AN, Auld PA. Serial studies of lung volume and VA-Q in hyaline membrane disease. Pediatr Res 1973; 7: 82-88.

68. Krauss AN, Auld PA. Measurement of functional residual capacity in distressed neonates by helium rebreathing. $J$ Pediatr 1970; 77: 228-232.

69. Bancalari E, Garcia OL, Jesse MJ. Effects of continuous negative pressure on lung mechanics in idiopathic respiratory distress syndrome. Pediatrics 1973; 51: 485-493.

70. Richardson P, Bose CL, Carlstrom JR. The functional residual capacity of infants with respiratory distress syndrome. Acta Paediatr Scand 1986; 75: 267-271.

71. Edberg KE, Sandberg K, Silberberg A, Ekstrom-Jodal B, Hjalmarson O. Lung volume, gas mixing, and mechanics of breathing in mechanically ventilated very low birth weight infants with idiopathic respiratory distress syndrome. Pediatr Res 1991; 30: 496-500. 
72. Vilstrup CT, Bjorklund LJ, Larsson A, Lachmann B, Werner O. Functional residual capacity and ventilation homogeneity in mechanically ventilated small neonates. $J$ Lab Physiol 1992; 73: 276-283.

73. Gerhardt T, Bancalari E. Chest wall compliance in fullterm and premature infants. Acta Paediatr Scand 1980; 69: 359-364.

74. Goldsmith LS, Greenspan JS, Rubenstein SD, Wolfson MR, Shaffer TH. Immediate improvement in lung volume after exogenous surfactant: alveolar recruitment versus increased distention. J Pediatr 1991; 119: 424-428.

75. Hatch DJ, Taylor BW. Thoracic gas volume in early childhood. Arch Dis Child 1976; 51: 859-864.

76. Boushy SF, North LB. Pulmonary function in infiltrative lung disease. Chest 1973; 64: 448-453.

77. Gibson GJ, Pride NB. Pulmonary mechanics in fibrosing alveolitis: the effects of lung shrinkage. Am Rev Respir Dis 1977; 116: 637-647.

78. Gibson GJ, Pride NB. Lung distensibility; the static pressure volume curve of the lungs and its use in clinical assessment. Br J Dis Chest 1976; 70: 143-184.

79. Bradvik I, Wollmer P, Simonsson B, Albrechtsson U, Lyttkens K, Jonson B. Lung mechanics and their relationship to lung volumes in pulmonary sarcoidosis. Eur Respir J 1989; 2: 643-651.

80. Gibson GJ, Pride NB, Newsom-Davis J, Loh LC. Pulmonary mechanics in patients with respiratory muscle weakness. Am Rev Respir Dis 1977; 115: 389-395.

81. De Troyer A, Borenstein S. Acute changes in respiratory mechanics after pyridostigmine injection in patients with myasthenia gravis. Am Rev Respir Dis 1980; 121: 629_ 638.

82. De Troyer A, Borenstein S, Cordier R. Analysis of lung volume restriction in patients with respiratory muscle weakness. Thorax 1980; 35: 603-610.

83. Pitcher-Wilmott R, Shutack JG, Fox WW. Decreased lung volume after nasogastric feeding of neonates recovering from respiratory disease. J Pediatr 1979; 95: 119121.

84. Ray CS, Sue DY, Bray G, Hansen JE, Wasserman K. Effects of obesity on respiratory function. Am Rev Respir Dis 1983; 128: 501-506.

85. Enright PL, Kronmal RA, Higgens M, Schenker M, Haponik EF. Spirometry reference values for women and men 65-85 years of age. Am Rev Respir Dis 1993; 147: $125-133$.

86. Lopata M, Onal E. Mass loading, sleep apnea, and the pathogenesis of obesity hypoventilation. Am Rev Respir Dis 1982; 126: 640-645.

87. Rochester DF, Enson Y. Current concepts in the pathogenesis of the obesity-hypoventilation syndrome. Am J Med 1974; 57: 402-420.

88. Fadell IJ, Richman AD, Ward WW, Hendon JR. Fatty infiltration of respiratory muscles in the Pickwickian Syndrome. N Engl J Med 1962; 266: 861-864.

89. Lisboa C, Moreno R, Rava M, Ferretti R, Cruz E. Inspiratory muscle function in patients with severe kyphoscoliosis. Am Rev Respir Dis 1985; 132: 48-52.

90. Caro CG, Butler J, DuBois AB. Some effects of restriction of chest cage expansion on pulmonary function in man: an experimental study. J Clin Invest 1960; 39: 573583.

91. Ellis ER, Grunstein RR, Chan S, Bye PTP, Sullivan CE. Noninvasive ventilatory support during sleep improves respiratory failure in kyphoscoliosis. Chest 1988; 94: 811815.

92. Fink A, Rivin A, Murray JF. Pectus excavatum; an analy- sis of twenty seven cases. Archives Int Med 1961; 108 : 427-437.

93. Mead J, Sly P, Le Souef P, Hibbert M, Phelan P. Rib cage mobility in pectus excavatum. Am Rev Respir Dis 1985; 132: $1223-1228$.

94. Henry RL, Milner AD, Stokes GM, Hodges IG, Groggins RC. Lung function after acute bronchiolitis. Arch Dis Child 1983; 58: 60-63.

95. Gibson GJ. Pulmonary hyperinflation: a clinical overview. Eur Respir J 1996; 9: 2640-2649.

96. Boon AW, Ward McQuaid JM, Milner AD, Hopkin IE. Thoracic gas volume, helium functional residual capacity and air-trapping in the first six hours of life: the effect of oxygen administration. Early Hum Dev 1981; 5: 157166.

97. Beardsmore CS, Stocks J, Silverman M. Problems in measurement of thoracic gas volume in infancy. $J$ Appl Physiol 1982; 52: 995-999.

98. Godfrey S, Beardsmore CS, Maayan C, Bar-Yishay E. Can thoracic gas volume be measured in infants with airways obstruction? Am Rev Respir Dis 1986; 133: 245251.

99. Yeh TF, Lilien LD, Barathi A, Pildes RS. Lung volume, dynamic lung compliance, and blood gases during the first 3 days of postnatal life in infants with meconium aspiration syndrome. Crit Care Med 1982; 10: 588-592.

100. Gerhardt T, Hehre D, Feller R, Reifenberg L, Bancalari E. Serial determination of pulmonary function in infants with chronic lung disease. J Pediatr 1987; 110: 448-456.

101. Hird MF, Greenough A, Mieli-Vergani G, Mowat AP. Hyperinflation in children with liver disease due to alpha1-antitrypsin deficiency. Pediatr Pulmonol 1991; 11: 212216.

102. Wall M, Moe E, Eisenberg J, Powers M, Buist N, Buist AS. Long-term follow-up of a cohort of children with alpha-1-antitrypsin deficiency. J Pediatr 1990; 116: 248251.

103. Silvers GW, Petty TL, Stanford RE. Elastic recoil changes in early emphysema. Thorax 1980; 35: 490-495.

104. Vulterini S, Bianco MR, Pellicciotti L, Sidoti AM. Lung mechanics in subjects showing increased residual volume without bronchial obstruction. Thorax 1980; 35: 461466.

105. Rubin AE, Bruderman I. Overdistension of lung due to peripheral airways obstruction. Chest 1973; 63: 948-951.

106. McFadden ERJ. Exertional dyspnea and cough as preludes to acute attacks of bronchial asthma. $N$ Engl J Med 1975; 292: 555-559.

107. Peress L, Sybrecht G, Macklem PT. The mechanism of increase in total lung capacity during acute asthma. Am J Med 1976; 61: 165-169.

108. Petty TL, Silvers GW, Stanford RE. Mild emphysema is associated with reduced elastic recoil and increased lung size but not with air-flow limitation. Am Rev Respir Dis 1987; 136: 867-871.

109. West WW, Nagai A, Hodgkin JE, Thurlbeck WM. The National Institutes of Health intermittent positive pressure breathing trial-pathology studies: the diagnosis of emphysema. Am Rev Respir Dis 1987; 135: 123-129.

110. Rodenstein DO, Stanescu DC. Frequency dependence of plethysmographic volume in healthy and asthmatic subjects. J Appl Physiol 1983; 54: 159-165.

111. Woolcock AJ, Read J. Lung volumes in exacerbations of asthma. Am J Med 1966; 41: 259-273.

112. Blackie SP, Al-Majed S, Staples CA, Hilliam C, Pare PD. Changes in total lung capacity during acute spontaneous asthma. Am Rev Respir Dis 1990; 142: 79-83. 
113. Eidelman DH, Lei M, Ghezzo RH. Morphometry of methacholine-induced bronchoconstriction in the rat. $J$ Appl Physiol 1993; 75: 1702-1710.

114. Greaves LA, Colebatch HJH. Large lungs after childhood asthma: a consequence of enlarged airspaces. Aust $N Z J$ Med 1985; 15: 427-434.

115. Buhain WJ, Brody JS, Fisher AB. Effect of artificial airway obstruction on elastic properties of the lung. $J$ Appl Physiol 1972; 33: 589-594.

116. Merkus PJFM, van Essen-Zandvliet EE, Kouwenberg JM, et al. Large lungs after childhood asthma; a case-control study. Am Rev Respir Dis 1993; 148: 1484-1489.

117. Sandberg K, Sjoqvist BA, Hjalmarson O, Olsson T. Lung function in newborn infants with tachypnea of unknown cause. Pediatr Res 1987; 22: 581-586.

118. Bryan MH, Hardie MJ, Reilly BJ, Swyer PR. Pulmonary function studies during the first year of life in infants recovering from the respiratory distress syndrome. Pediatrics 1973; 52: 169-178.

119. Collett PW, Brancatisano T, Engel LA. Changes in the glottic aperture during bronchial asthma. Am Rev Respir Dis 1983; 128: 719-723.

120. Cormier Y, Lecours R, Legris C. Mechanisms of hyperinflation in asthma. Eur Respir J 1990; 3: 619-624.

121. Martin J, Powell E, Shore S, Emrich J, Engel LA. The role of respiratory muscles in the hyperinflation of bronchial asthma. Am Rev Respir Dis 1980; 121: 441-447.

122. Ryan ML, Hedrick MS, Pizarro J, Bisgard GE. Carotid body noradrenergic sensitivity in ventilatory acclimatization to hypoxia. Respir Physiol 1993; 92: 77-90.

123. Pellegrino R, Brusasco V. On the causes of lung hyperinflation during bronchoconstriction. Eur Respir J 1997; 10: 468-475.

124. O'Donnell DE, Sanii R, Anthonisen NR, Younes M. Effect of dynamic airway compression on breathing pattern and respiratory sensation in severe chronic obstructive pulmonary disease. Am Rev Respir Dis 1987; 135: 912-918.

125. Lougheed MD, Lam M, Forkert L, Webb KA, O'Donnell DE. Breathlessness during acute bronchoconstriction in asthma. Am Rev Respir Dis 1993; 148: 1452-1459.

126. Guignon I, Cassart M, Gevenois PA, et al. Persistent hyperinflation after heart-lung transplantation for cystic fibrosis. Am J Respir Crit Care Med 1995; 151: 534-540.

127. Butler J, Schrijen F, Henriquez A, Polu JM, Albert RK. Cause of the raised wedge pressure on exercise in chronic obstructive pulmonary disease. Am Rev Respir Dis 1988; 138: $350-354$.
128. O'Donnell DE, Webb KA. Exertional breathlessness in patients with chronic airflow limitation; the role of lung hyperinflation. Am Rev Respir Dis 1993; 148: 1351-1357.

129. O'Donnell DE. Breathlessness in patients with chronic airflow limitation; mechanisms and management. Chest 1994; 106: 904-912.

130. Rehder K, Marsh HM. Respiratory mechanics during anesthesia and mechanical ventilation. In: Fishman AP, ed. Handbook of Physiology, Section 3, The Respiratory System. Bethesda, MD, American Physiological Society, 1986; pp. 737-752.

131. De Troyer A, Martin JG. Respiratory muscle tone and the control of functional residual capacity. Chest 1983; 84: 3-4.

132. Westbrook PR, Stubbs SE, Sessler AD, Rehder K, Hyatt RE. Effects of anesthesia and muscle paralysis on respiratory mechanics in normal man. J Appl Physiol 1973; 34: 81-86.

133. Fletcher ME, Stack C, Ewart M, et al. Respiratory compliance during sedation, anesthesia, and paralysis in infants and young children. J Appl Physiol 1991; 70: 1977-1982.

134. Dueck R, Trutow RJ, Davies NJH, Clausen JL, Davidson TM. The lung volume at which shunting occurs with inhalation anesthesia. Anesthesiology 1988; 69: 854-861.

135. Hedenstierna G, Lofstrom B, Lundh R. Thoracic gas volume and chest-abdomen dimensions during anesthesia and muscle paralysis. Anesthesiology 1981; 55: 499-506.

136. Krayer S, Rehder K, Beck KC, Cameron PD, Didier EP, Hoffman EA. Quantification of thoracic volumes by threedimensional imaging. J Appl Physiol 1987; 62: 591-598.

137. Damia G, Mascheroni D, Croci M, Tarenzi L. Perioperative changes in functional residual capacity in morbidly obese patients. Br J Anaesth 1988; 60: 574-578.

138. Geubelle F, Francotte M, Beyer M, Louis I, Logvinoff MM. Functional residual capacity and thoracic gas volume in normoxic and hyperoxic new-born infants. Acta Paediatr Belg 1977; 30: 221-225.

139. Newth CJL, Enright P, Johnson RL Jr. Multiple breath nitrogen washout techniques: including measurements with patients on ventilators. Eur Respir J 1997; 10: 2174 2185.

140. Ploysongsang V, Schonfeld SA. Mechanism of production of crackles after atelectasis during low-volume breathing. Am Rev Respir Dis 1982; 126: 413-415.

141. Garfinkel F, Fitzgerald RS. The effect of hyperoxia, hypoxia and hypercapnia on FRC and occlusion pressure in human subjects. Respir Physiol 1978; 33: 241-250. 